\title{
Commentary: An ex utero fetal sheep model breathes fresh air into the study of neurodevelopment
}

Caroline A. McElhannon, BS, Joseph W. Turek, MD, PhD, and Nicholas D. Andersen, MD

From the Duke Congenital Heart Research \& Training Laboratory, Duke University, Durham, NC.

Disclosures: Authors have nothing to disclose with regard to commercial support.

Received for publication Aug 7, 2019; revisions received Aug 7, 2019; accepted for publication Aug 7, 2019; available ahead of print Oct 9, 2019

Address for reprints: Nicholas D. Andersen, MD, Division of Cardiovascular and Thoracic Surgery, Duke University Medical Center, 2301 Erwin Rd, DUMC 3474, Durham, NC 27710 (E-mail: Nicholas.andersen@ duke.edu).

J Thorac Cardiovasc Surg 2020;159:282-3

$0022-5223 / \$ 36.00$

Copyright $(2019$ by The American Association for Thoracic Surgery

https://doi.org/10.1016/j.jtcvs.2019.08.068

The etiology of neurocognitive disabilities commonly present in children with congenital heart disease (CHD) remains an important topic of inquiry and debate. ${ }^{1}$ In the current issue of The Journal of Thoracic and Cardiovascular Surgery, Lawrence and colleagues report the results of a follow-up study of neurologic development under conditions of prenatal hypoxemia, using an ex utero fetal sheep model (Figure. 1). ${ }^{2}$ Using this model, the authors have previously shown an impairment in myelination and reduction in neurogenesis as a result of hypoxemia during fetal development. ${ }^{3}$ In additional experiments from the same animals, the authors now report no increase in apoptosis or inflammatory lesions involving astrocyte or microglial clusters in any experimental group, but hypoxic animals did show a significant increase in round/amoeboid type microglia, potentially signifying increased microglial activation or immaturity. ${ }^{2}$ These results show that prenatal hypoxemia can alter the morphology of microglia, which normally contribute significantly to neurodevelopment through the establishment of neural circuits and promotion of myelinogenesis. ${ }^{4,5}$ This study therefore presents important additional information related to the cause and potential future therapies for neuropathology in children with cyanotic heart defects.

Although neurocognitive disabilities are prevalent among children with CHD, previous research has yielded limited success in identifying the source of this neuropathology or potential therapeutic targets. However, the development of an "artificial womb" ex utero model provides a physiologically representative and feasible model for study of normal and pathologic prenatal conditions. ${ }^{6}$ Although this report shows the model's utility for the study of CHD, the potential research avenues that stem from such a groundbreaking advancement extend vastly to various other diseases and congenital disorders.

Additionally, this article provides further evidence for a multifactorial contribution to the neurocognitive disabilities

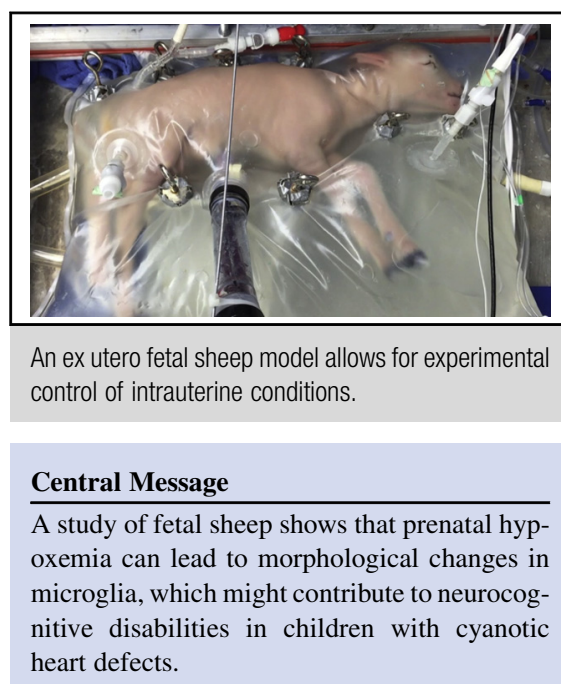

See Article page 270.

often seen in children with a CHD. Previously, the development of these complications had commonly been attributed to the insult of major surgery undertaken at a young age. However, the results of this article show that, although surgery still has its risks and possible detrimental contributions, other factors, such as prenatal hypoxemia, could potentially play a substantial role in neurocognitive delays. As with many medical conditions and situations, it seems the answer might not be as simple as originally assumed.

In summary, the article by Lawrence and colleagues shows that exposure of fetal sheep to conditions of hypoxemia can lead to morphological changes in microglia, which might contribute to neurocognitive disabilities in children with cyanotic heart defects. This study provides

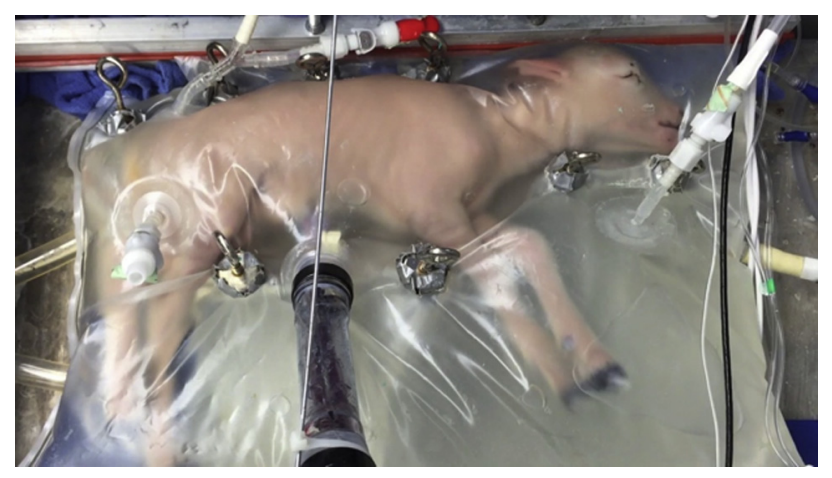

FIGURE 1. An ex utero fetal sheep model allows for experimental control of intrauterine conditions. 
compelling support for a multifactorial contribution to the neurodevelopmental disabilities often observed in children with CHD. Further, through the successful use of an ex utero large animal model, the study shows the vast possibilities of this new experimental design for research into normal and abnormal development, and breathes life into a new era of intrauterine research.

\section{References}

1. Marino BS, Lipkin PH, Newburger JW, Peacock G, Gerdes M, Gaynor JW, et al. Neurodevelopmental outcomes in children with congenital heart disease: evaluation and management: a scientific statement from the American Heart Association. Circulation. 2012;126:1143-72.
2. Lawrence KM, McGovern PE, Mejaddam A, Rossidis AC, Baumgarten H Kim AG, et al. Prenatal hypoxemia alters microglial morphology in fetal sheep. J Thorac Cardiovasc Surg. 2020;159:270-7.

3. Lawrence KM, McGovern PE, Mejaddam A, Rossidis AC, Baumgarten H, Kim A, et al. Chronic intrauterine hypoxia alters neurodevelopment in fetal sheep. $J$ Thorac Cardiovasc Surg. 2019;157:1982-91.

4. Hagemeyer N, Hanft KM, Akriditou MA, Unger N, Park ES, Stanley ER et al. Microglia contribute to normal myelinogenesis and to oligodendrocyte progenitor maintenance during adulthood. Acta Neuropathol. 2017;134: 441-58.

5. Wlodarczyk A, Holtman IR, Krueger M, Yogev N, Bruttger J, Khorooshi R, et al A novel microglial subset plays a key role in myelinogenesis in developing brain EMBO J. 2017:36:3292-308

6. Partridge EA, Davey MG, Hornick MA, McGovern PE, Mejaddam AY, Vrecenak JD, et al. An extra-uterine system to physiologically support the extreme premature lamb. Nat Commun. 2017;8:15112. 